\title{
Direitos humanos e globalização econômica: notas para uma discusão
}

\author{
JOSÉ EDUARDO FARIA
}

$\mathrm{C}$ OMO FICAM os direitos humanos com o fenômeno da globalização econômica? A reorganização dos processos produtivos, a transnacionalização dos mercados e a volatilidade dos capitais financeiros estão ampliando a efetividade da democracia? Ou, pelo contrário, vêm limitando o alcance de seus mecanismos de representação e controle político? Por sua vez, as instituições jurídicas encarregadas de processar, neutralizar e decidir conflitos, como os tribunais e o ministério público, têm condições de manter intocadas suas prerrogativas, suas competências funcionais, sua independência e seu campo de atuação num período histórico fortemente marcado pela compressão do tempo e do espaço?

O objetivo neste trabalho não é responder a cada uma dessas indagações, mas, numa perspectiva jus-sociológica, apenas mapear o terreno da discussão. Seu ponto de partida é o impacto desagregador da transnacionalização dos mercados sobre as estruturas político-institucionais e sobre o tipo de ordem jurídica forjados pelo Estado-nação com base nos princípios da soberania e da territorialidade. Se hoje as decisões em matéria de moeda, pesquisa e desenvolvimento tecnológico, produção industrial e comercialização tendem, em progressão geométrica, a ser tomadas no âmbito de organismos multilaterais, conglomerados multinacionais, bancos, fundos de investimento, fundos de pensão e companhias seguradoras com atuação mundial, de que modo controlá-las por meio de mecanismos cujo alcance é basicamente circunscrito às fronteiras geográficas de cada país?

A globalização econômica - e este é apenas um juízo de fato, não de valor está substituindo a política pelo mercado, como instância privilegiada de regulação social. Por tornar os capitais financeiros muitas vezes imunes a fiscalizações governamentais, fragmentar as atividades produtivas em distintas nações, regiões e continentes e reduzir as sociedades a meros conjuntos de grupos e mercados unidos em rede, tal fenômeno vem esvaziando parte dos instrumentos de controle dos atores nacionais. À medida que o processo decisório foi sendo transnacionalizado, as decisões políticas tornaram-se crescentemente condicionadas por equilíbrios macroeconômicos que passaram a representar um efetivo princípio normativo responsável pelo estabelecimento de determinados limites às intervenções reguladoras e disciplinadoras dos governos. Sua autonomia decisória, como conseqüência, tornou-se progressivamente vulnerável a opções feitas em outros lugares, sobre as quais dirigentes, legisladores, magistrados e promotores têm reduzida capacidade 
de pressão e influência. Acima de tudo, ao gerar novas formas de poder, autônomas, desterritorializadas, a transnacionalização dos mercados debilitou o caráter essencial da soberania, fundado na presunção superiorem non recognoscens, e pôs em xeque tanto a centralidade quanto a exclusividade das estruturas jurídico-políticas do Estado-nação.

Não é difícil verificar como o fato vem ocorrendo. Diante do policentrismo que hoje caracteriza a economia globalizada, o direito positivo e suas instituições perdem uma parte significativa de sua jurisdição. Como foram concebidos para atuar dentro de limites territoriais precisos, com base nos instrumentos de violência monopolizados pelo Estado, seu alcance ou seu universo tende a diminuir na mesma proporção em que as barreiras geográficas vão sendo superadas pela expansão da microeletrônica, da informática, das telecomunicações e dos transportes. E quanto maior é a velocidade desse processo, mais os tribunais passam a ser atravessados pelas justiças emergentes, quer nos espaços infra-estatais (os locais, por exemplo) quer nos espaços supra-estatais. Os espaços infra-estatais estão sendo polarizados por formas inoficiais ou não-oficiais de resolução dos conflitos - como usos, costumes, diferentes estratégias de mediação, negociação e conciliação, autocomposição de interesses e auto-resolução de divergências, arbitragens privadas ou mesmo a imposição da lei do mais forte nos guetos inexpugnáveis controlados pelo crime organizado e pelo narcotráfico (constituindo assim uma espécie de direito marginal).

Já os espaços supra-estatais têm sido polarizados pelos mais diversos organismos multilaterais (Banco Mundial, Fundo Monetário Internacional, Organização Mundial do Comércio, Banco de Compensações Internacionais, Organização Mundial da Propriedade Intelectual, etc.), por conglomerados empresariais, instituições financeiras, entidades não-governamentais e movimentos representativos de uma sociedade civil supranacional. Além disso, a ordem jurídica do Estadonação atualmente enfrenta outra enorme limitação estrutural. Suas normas padronizadoras, editadas com base nos conhecidos princípios da impessoalidade, da generalidade e da abstração, tradicionalmente organizadas sob a forma de um sistema lógico-formal fechado e hierarquizado, são singelas demais para disciplinar ações crescentemente complexas. Elas não conseguem dar conta, de maneira lógica, da pluralidade de situações sociais, econômicas, políticas e culturais cada vez mais diferenciadas. Revelam-se igualmente incapazes de regular e disciplinar, guardando coerência sistêmica, fatos multifacetados e heterogêneos. Organizadas sob a forma de um código rigidamente binário (permitido/proibido, legal/ilegal e constitucional/inconstitucional), tais normas padronizadoras revelam-se ineficazes na regulamentação e tratamento de casos muito específicos e singulares (Willke, 1986; Teubner, 1996).

Como o Estado não pode deixar muitas dessas ações, fatos, situações e casos sem algum tipo de controle, ele se vê obrigado a editar normas ad hoc para casos altamente especializados. E quanto maior a sua produção normativa nessa linha, mais seu direito positivo perde organicidade e racionalidade sistêmica, dada sua pretensão de abarcar uma intrincada e por vezes contraditória pluralidade de interesses e comportamentos altamente particularísticos. 
Mas não é só. Viabilizada pela substituição das rígidas plantas industriais de caráter fordista por plantas mais leves, enxutas e flexíveis, a fragmentação das atividades produtivas dá aos conglomerados transnacionais extraordinário poder para barganhar e decidir a localização de suas unidades fabris. Dados do Centro de Estudos e Pesquisas sobre as Empresas Multinacionais da Universidade de Paris - X (Nanterre) informam que, no início da década de 80, os 886 maiores conglomerados transnacionais já controlavam $76 \%$ da produção manufatureira mundial (Latouche, 1996:102). Para definir os locais de instalação de suas plantas industriais, eles tendem a exigir dos poderes públicos isenções fiscais, subsídios, créditos favorecidos, infra-estrutura básica a custo zero e alterações drásticas nas legislações previdenciária, trabalhista e urbanística. E, lutando para atraí-las com a finalidade de alargar seu mercado de trabalho, cidades, nações e regiões muitas vezes entram numa competição predadora e selvagem. À medida em que essa competição leva o poder público a se indiferenciar ou confundir com o poder dos grupos empresariais, tal o número de concessões que é obrigado a fazer, o resultado acaba sendo a negação da fórmula smithiana da riqueza das nações. Isto porque não é mais o Estado que decide as taxas e os impostos a serem cobrados, mas, pelo contrário, são os conglomerados que escolhem onde e quanto irão pagá-los (Calgano et al., 1993:49-50, 65). Não é o Estado que impõe sua ordem jurídica sobre esses conglomerados; são eles que, podendo concentrar suas linhas de produção nos países que oferecerem as melhores contrapartidas para seus investimentos, acabam selecionando as legislações nacionais às quais irão se submeter.

Essa fragmentação geoespacial das atividades produtivas vem tornando possível uma ampliação sem precedentes do comércio intrafirmas (Petrella, 1996), com importantes conseqüências para as engrenagens jurídicas do Estado-nação. Hoje, pelo menos $1 / 3$ das atividades e negócios das 37 mil empresas transnacionais que atuam na economia globalizada - por meio de 200 mil filiais e subsidiárias - é realizado entre elas próprias. Tal expansão do comércio intrafirmas abre caminho para a ruptura da centralidade e da exclusividade do direito positivo nacional. Editado sob a forma de uma ordem jurídica postulada como lógica, coerente e livre de ambigüidades ou antinomias, esse direito é desafiado por regras e procedimentos normativos espontaneamente forjados no sistema econômico. São direitos autônomos, com normas, lógicas e processos próprios, entreabrindo a coexistência (por vezes sincrônica, por vezes conflitante) de diferentes normatividades; mais precisamente, de um pluralismo jurídico de natureza infra-estatal ou supraestatal (Santos, 1995). É esse o caso, por exemplo, da lex mercatoria, o corpo autônomo de práticas, regras e princípios constituído pela comunidade empresarial transnacional para autodisciplinar suas relações. É esse, também, o caso do direito da produção, o conjunto de normas técnicas formuladas, entre outros objetivos, para atender às exigências de padrões mínimos de qualidade e segurança dos bens e serviços em circulação no mercado transnacionalizado, de especificação de seus componentes, da origem de suas matérias primas etc.

O resultado desse pluralismo jurídico, como está ilustrado pelo quadro a seguir, acaba levando, no plano infra-estatal, ao advento de justiças profissionais (especializadas em conciliação e arbitragem) e não-profissionais (as comunitárias, 
por exemplo), ambas operadas basicamente com critérios de racionalidade material e circunscrevendo sua atuação a conflitos intragrupos, intracomunidade e intraclasses. E, no plano supra-estatal, propiciando a proliferação de foros descentralizados de negociação (como a Chambre International du Commerce e a Camera di Commercio, Industria, Artigianato e Agricoltura di Milano) e a multiplicação de órgãos técnico-normativos (como a International Organization for Standardization e o Accounting Standards Committee) (Gessner, 1995; Olgiati, 1997). Criados especialmente para fixar parâmetros de qualidade, estabelecer padrões de segurança, homologar pesquisas, dar pareceres e também promover arbitragens, esses foros de negociação e arbitragem e esses órgãos técnico-normativos tendem, na maioria absoluta dos casos, a oferecer processos de resolução dos conflitos muito mais rápidos, baratos e eficien-tes do que os judiciais.

Tipo de ordens normativas

\begin{tabular}{|c|c|c|c|c|}
\hline Características & $\begin{array}{l}\text { Lex mercatoria/ } \\
\text { Direito da produção }\end{array}$ & $\begin{array}{l}\text { Normatividade } \\
\text { auto-produzida } \\
\text { pelas partes/ } \\
\text { Direito inoficial }\end{array}$ & $\begin{array}{l}\text { Direito } \\
\text { positivo }\end{array}$ & $\begin{array}{l}\text { Direito } \\
\text { marginal }\end{array}$ \\
\hline $\begin{array}{l}\text { O que está } \\
\text { em jogo }\end{array}$ & $\begin{array}{l}\text { Tensões não- } \\
\text { declaradas } \\
\text { publicamente }\end{array}$ & $\begin{array}{l}\text { Conflitos } \\
\text { materiais }\end{array}$ & $\begin{array}{l}\text { Litígios } \\
\text { jurídico- } \\
\text { processuais }\end{array}$ & Agressões \\
\hline Objetivos & Relações & $\begin{array}{l}\text { Soluções } \\
\text { substantivas }\end{array}$ & $\begin{array}{l}\text { Soluções } \\
\text { formais }\end{array}$ & Contestação \\
\hline Tipos de norma & $\begin{array}{l}\text { Pragmático } \\
\text { e casuísta }\end{array}$ & Soluções $a d$ hoc & $\begin{array}{l}\text { Direito } \\
\text { codificado }\end{array}$ & $\begin{array}{l}\text { Lei do } \\
\text { mais forte }\end{array}$ \\
\hline Racionalidade & Procedimental & Material & Formal & Irracional \\
\hline $\begin{array}{l}\text { Modo } \\
\text { de formalização }\end{array}$ & Contratual & Negociação & Aplicação & $\begin{array}{c}\text { Ausência } \\
\text { de formalização }\end{array}$ \\
\hline $\begin{array}{l}\text { Tipo } \\
\text { de procedimento }\end{array}$ & $\begin{array}{l}\text { Transação/ } \\
\text { mediação }\end{array}$ & $\begin{array}{l}\text { Conciliação/ } \\
\text { Arbitragem }\end{array}$ & Decisão & Repressão \\
\hline $\begin{array}{l}\text { Grau de } \\
\text { institucionalização }\end{array}$ & $\begin{array}{l}\text { Organização flexível } \\
\text { e sistemas } \\
\text { auto-regulados }\end{array}$ & $\begin{array}{l}\text { Campo social } \\
\text { semi-autônomo }\end{array}$ & $\begin{array}{l}\text { Campo } \\
\text { normativo } \\
\text { estatal }\end{array}$ & Marginalidade \\
\hline $\begin{array}{l}\text { Efetividade } \\
\text { do Direito }\end{array}$ & $\begin{array}{l}\text { Por aceitação } \\
\text { e por inclusão }\end{array}$ & $\begin{array}{l}\text { Por adaptação } \\
\text { ao contexto } \\
\text { sócio-econômico }\end{array}$ & $\begin{array}{l}\text { Pretensão de } \\
\text { aplicabilidade } \\
\text { universal }\end{array}$ & Desafio \\
\hline
\end{tabular}

Diante da integração dos sistemas produtivo e financeiro em escala mundial, do enfraquecimento do poder de controle e intervenção sobre fluxos internacionais de capitais pelos bancos centrais e da crescente autonomia de setores econô- 
micos funcionalmente diferenciados e especializados, com suas racionalidades específicas e muitas vezes incompatíveis entre si levando à ampliação do pluralismo de ordens normativas, o Estado-nação se encontra diante de um impasse. Por um lado, já não consegue mais disciplinar e regular sua sociedade e sua economia exclusivamente por meio de seus instrumentos jurídicos tradicionais. Com as intrincadas tramas e entrelaçamentos promovidos pelos diferentes setores econômicos no âmbito dos mercados transnacionalizados, seu ordenamento jurídico, suas instituições judiciais têm alcance cada vez mais reduzido e operacionalidade cada vez mais limitada. Por outro lado, sem condições de assegurar a eficaz regulação direta e centralizadora das situações sociais e econômicas, pressionado pela multiplicação das fontes materiais de direito, perdendo progressivamente o controle da racionalidade sistêmica de seus códigos ao substituir as tradicionais normas abstratas, genéricas e impessoais por normas particularizantes, específicas e finalísticas, e ainda tendo seu ordenamento submetido a uma crescente competição com outros ordenamentos, o Estado-nação atinge os limites fáticos de sua soberania. Tal aspecto fica particularmente evidente quando é constrangido a negociar com forças econômicas que transcendem o nível nacional, condicionando seus investimentos à aceitação de seus valores, de suas regras, de seus procedimentos e de seus mecanismos particulares de resolução de conflitos, por parte do poder público.

Essa soberania compulsoriamente partilhada, sob pena de acabar ficando à margem da economia globalizada, tem obrigado o Estado-nação a rever sua política legislativa, a reformular a estrutura de seu direito positivo e a redimensionar a jurisdição de suas instituições judiciais amplas e ambiciosas estratégias de desregulamentação, deslegalização e desconstitucionalização, implementadas paralelamente à promoção da ruptura dos monopólios públicos. A noção dessa estratégia é justificada, entre outros fatores, por uma espécie de cálculo de custo/ benefício feito pelos dirigentes e pelos legisladores. Sem ter como ampliar a complexidade de seu ordenamento jurídico e de seu aparato judicial em nível equivalente de complexidade e diferenciação funcional dos diferentes sistemas sócioeconômicos, eles passam a agir pragmaticamente. Afinal, se quanto mais tentam disciplinar e intervir, menos conseguem ser eficazes, obter resultados satisfatórios, manter a coerência lógica e assegurar a organicidade de seu direito positivo, não lhes resta outro caminho para preservar sua autoridade funcional: quanto menos procurarem disciplinar e intervir, menor será o risco de acabarem desmoralizados pela inefetividade de seu instrumental regulatório e de seus mecanismos de controle.

A conseqüência desse processo de desregulamentação, deslegalização e desconstitucionalização, longe de conduzir a um vazio jurídico, abre caminho para uma intrincada articulação de sistemas e subsistemas sócio-econômicos internos e externos. Parte significativa do direito positivo do Estado-nação, por exemplo, hoje vem sendo internacionalizada pela expansão da lex mercatoria e do direito da produção e por suas relações com as normas emanadas dos organismos multilaterais (Santos, 1995). Outra parte, por sua vez, vem sendo minada pela força constitutiva de situações criadas pelos detentores do poder econômico; e, como conseqüência, vem sendo substituída pelo veloz crescimento do número de normas privadas, no plano infranacional, à medida em que cada corporação empresa- 
rial tende a criar as regras de que precisa e a jurisdicizar suas respectivas áreas e espaços de atuação segundo suas conveniências. A desregulamentação e a deslegalização em nível do Estado significam, desta maneira, a re-regulamentação e a relegalização em nível dos próprios sistemas sócio-econômicos (Santos, 1995); mais precisamente, em nível das organizações privadas capazes de efetuar investimentos produtivos, oferecer empregos, gerar receita tributária, impor comportamentos etc.

Nesse cenário, o que resta do direito positivo forjado pelo Estado-nação com base no dogma da completude no princípio da coerência, no postulado da inexistência de lacunas e de antinomias e, nos primados da previsibilidade, da certeza e da segurança? Depois dos processos de publicização do direito privado e administrativização do direito público ocorridos no âmbito dos Welfare States entre os anos de 40 e 70, o que se tem a partir da década de 80 é um ordenamento jurídico sem centralidade e exclusividade (Teubner, 1987); em outras palavras, um ordenamento constituído como mais um sistema normativo, entre vários outros igualmente válidos; e, o que é mais importante, um ordenamento que se destaca por sua legislação descodificada. Em linhas gerais, tal legislação é formada por normas de comportamento, normas de organização e normas programáticas que, se intercruzando continuamente, terminam por produzir inúmeros micro-sistemas e distintas cadeias normativas no âmbito do ordenamento jurídico estatal. Assumindo assim a forma de redes, esses micro-sistemas legais e essas cadeias normativas caracterizam-se pela extrema multiplicidade e heterogeneidade de suas regras; pela flagrante provisoriedade e mutabilidade de suas engrenagens normativas; pelo acolhimento de uma pluralidade de pretensões contraditórias e, muitas vezes, excludentes. Num ordenamento com tais características, por isso mesmo, a idéia de interesses gerais e universais já não consegue mais exercer o papel de princípio totalizador destinado a compor, integrar e harmonizar os distintos interesses específicos. Ela pode até continuar preservada retoricamente nos textos legais, sobrevivendo aos processos de deslegalização e desconstitucionalização, mas já não tem mais o mesmo peso simbólico e funcional detido à época do advento do Estado constitucional, da democracia representativa e das declarações de direitos.

À luz de todas essas mudanças, as perguntas formuladas no início deste trabalho, relativas à efetividade dos direitos humanos e da democracia no âmbito da economia globalizada, encontram respostas algo céticas. Se os direitos humanos nasceram contra o Estado, ou seja, como forma de coibir a interferência arbitrária do poder público na esfera individual, o que pode acontecer com eles agora que o Estado-nação entra em reflexo com a transnacionalização dos mercados? Se os direitos humanos são inseparáveis de garantias fundamentais e se estas somente podem ser instrumentalizadas por meio do próprio poder público, como podem ser eles eficazes no momento em que esse mesmo poder é relativizado pelo fenômeno da globalização? Com a democracia, as indagações não são diferentes. Qual é seu alcance real, num período histórico em que a política perde para o mercado seu papel como instância privilegiada de deliberação e decisão? De que modo os vencedores no âmbito de eleições democráticas podem realizar as promessas feitas em sua campanha aos eleitores, principalmente em matéria de controle dos fluxos 
de capitais, uma vez que o alcance de suas medidas legislativas ou executivas é circunscrito ao espaço territorial do Estado-nação? Em que medida a transnacionalização dos mercados e a desterritorialização das decisões não minam o significado do voto e da representação popular? Se é certo que a esfera da política vem sendo esvaziada pela esfera da economia e que esta, por sua vez, vem sendo cada vez menos determinada pelos Estados e cada vez mais condicionada pelos conglomerados transnacionais, sem compromisso algum com o ambiente em que atuam, a quem cobrar responsabilidades? Que tipo de direito fundamental pode ser invocado e que tribunal pode ser acionado?

Institucionalizada a partir das lutas anti-absolutistas no século XVIII e da expansão dos movimentos codificados no século XIX, a democracia representativa, como é sabido, foi construída e consolidada ao longo de um processo histórico marcado pelo reconhecimento de três gerações de direitos humanos: os relativos à cidadania civil e política, que se destacam pelo direito às liberdades de locomoção, pensamento, voto, iniciativa, propriedade e disposição da vontade; os relativos às cidadania social e econômica, que se destacam pelo direito à educação, à saúde, à segurança social e ao bem-estar tanto individual quanto coletivo concedidos à classes trabalhadoras; os relativos à cidadania pós-material, que se destacam pelo direito à qualidade de vida, ao meio ambiente saudável, à tutela dos interesses difusos e ao reconhecimento da diferença, da singularidade e da subjetividade (Bendix, 1977; Ferry \& Renault, 1985; Capella, 1993; Santos, 1995). Essas três gerações de direitos humanos gravitam, em maior ou menor grau, em torno do Estado. A primeira o enquadra por meio da promulgação de uma ordem constitucional garantidora dos direitos individuais e das liberdades públicas; a segunda requer sua atuação eficaz na regulação dos mercados, na implementação de políticas distributivas e na promoção de transferências de renda no âmbito da sociedade; a terceira pressupõe o fortalecimento dos poderes das instituições encarregadas de assegurar a proteção dos interesses pós-materiais, como é o caso dos tribunais e do ministério público.

A cada nova geração dos direitos humanos, conforme se vê, um dos poderes do Estado-nação - respectivamente, o Legislativo, o Executivo e o aparato judicial, incluindo-se aí o Ministério Público - é afirmado, destacado e enfatizado. Com o fenômeno da globalização, no entanto, conforme já se viu, todos eles são funcionalmente esvaziados ou relativizados. Por isso, as três gerações de direitos humanos acabam enfrentando problemas para ser efetivadas. Seus valores básicos - liberdades públicas, igualdade substantiva e afirmação dos interesses pós-materiais colidem frontalmente com os imperativos categóricos da transnacionalização dos mercados, dos quais se destacam a eficácia, a produtividade e a competitividade. O cálculo econômico e a razão produtiva, em outras palavras, revelam-se potencialmente incompatíveis com os princípios básicos de convivência e sociabilidade no âmbito de formas organizacionais e institucionais dotadas de um mínimo de legitimidade jurídica e equilíbrio social.

Como no choque entre as panelas de ferro e de barro sempre quebra a mais fraca, não é difícil identificar as conseqüências desse tipo de colisão. À medida que 
a dinâmica da acumulação privada e a mobilidade dos capitais já não são mais controladas pelo Estado-nação, os direitos humanos e a democracia representativa, numa visão basicamente juridicista, parecem estar ingressando numa fase regressiva. Eles podem até continuar existindo no plano jurídico-positivo, sobrevivendo em termos formais aos processos de desregulamentação, deslegalização e desconstitucionalização já anteriormente mencionados. Contudo, já não são mais efetivamente implementados no plano real (se é que o foram, integralmente, um dia). Hoje, quando eventualmente isso ocorre, sua aplicação tende a ser seletiva (Santos, 1995). Entre outros motivos porque - conforme também já se viu - as decisões jurídicas, em sua grande maioria, não são mais necessariamente implementadas por atos de autoridade capazes de suscitar obediência, dependendo, pelo contrário, de negociações entre decisores e destinatários para serem eficazes. Em tal cenário, cada vez mais as decisões dotadas de enforcement não são as relativas aos direitos humanos, mas as destinadas a neutralizar os perversos efeitos desagregadores da globalização na vida social.

Como o avanço desse fenômeno está aprofundando a desigualdade e a exclusão, uma vez que os ganhos de produtividade em grande parte têm sido obtidos às custas da degradação salarial, da informatização da produção e do subseqüente fechamento dos postos de trabalho convencional, a simbiose entre marginalidade econômica e marginalidade social obriga as instituições jurídicas do Estado-nação a concentrar sua atuação na preservação da ordem, da segurança e da disciplina. Com a globalização econômica, em outras palavras, os excluídos dos mercados de trabalho e consumo perdem progressivamente as condições materiais para exercer os direitos humanos de primeira geração e para exigir o cumprimento dos direitos humanos de segunda e terceira geração; tornam-se supérfluos no âmbito do paradigma vigente, passando a viver sem leis protetoras efetivamente garantidas em sua universalidade. Condenados à marginalidade sócio-econômica e, por conseqüência a condições hobbesianas de vida, eles não mais aparecem como portadores de direitos subjetivos públicos. Nem por isso, contudo, são dispensados das obrigações e deveres estabelecidos pela legislação. Com suas normas penais, o Estado os mantém vinculados ao sistema jurídico basicamente em suas feições marginais, ou seja, como transgressores de toda natureza.

Diante da ampliação das desigualdades sociais, setoriais e regionais dos bolsões de miséria e guetos quarto-mundializados nos centros urbanos, da criminalidade e da propensão à desobediência coletiva, as instituições judiciais do Estado, antes voltadas ao desafio de proteger os direitos civis e políticos e de conferir eficácia aos direitos sociais e econômicos, acabam agora tendendo a assumir funções eminentemente punitivo-repressivas. Para tanto, a concepção de intervenção mínima e última do direito penal é alterada radicalmente (Adorno, 1996). Tal mudança tem por objetivo torná-lo mais abrangente, rigoroso e severo para disseminar o medo e o conformismo no seu público-alvo - os excluídos. Por isso, enquanto no âmbito dos direitos basicamente sociais e econômicos se vive hoje um período de reflexo e flexibilização, no direito penal se tem uma situação diametralmente oposta: veloz e intensa definição de novos tipos penais; crescente jurisdicização e criminalização de várias atividades em inúmeros setores na vida 
social; enfraquecimento dos princípios da legalidade e da tipicidade, por meio do recurso a normas com textura aberta (isto é, regras porosas, sem conceitos precisos); ampliação do rigor de penas já cominadas e de severidade das sanções; encurtamento das fases de investigação criminal e instrução processual; inversão do ônus da prova, passando-se a considerar culpado quem, uma vez acusado, não provar sua inocência.

Posta a discussão em termos estritamente juridicistas, portanto, as condições atuais para a efetividade dos direitos humanos e da democracia representativa no âmbito da economia globalizada parecem nebulosas e cinzentas. Esse ceticismo, porém, em hipótese alguma deve ser entendido como desqualificação das lutas pelo reconhecimento dos direitos humanos por considerá-las inviáveis a priori. Encarados numa perspectiva menos jurídica e mais política, na qual se destacam por sua dimensão muitas vezes utópica e/ou revolucionária, os direitos humanos podem propiciar ações incertas quanto à obtenção de resultados concretos no curto prazo, tendo em vista os problemas aqui apontados, mas potencialmente desafiadores e transformadores a médio e longo prazos. Isso já foi percebido por quem vem encarando os direitos humanos fora das relações de poder situadas no âmbito estatal; mais precisamente, concentrando sua atenção nas relações de poder existentes nos distintos contextos da vida social, identificando-os como espaços de democratização (Lechner, 1993; Santos, 1995). Lutar pela universalização e efetivação dos direitos humanos significa, em tal perspectiva, implementar e executar programas emancipatórios no âmbito desses espaços não-estatais. Programas cujo valor básico é o princípio da reciprocidade, ou seja, o reconhecimento do outro como homens livres e iguais, permitindo assim que as múltiplas formas de cidadania - a política, a econômica, a social, a cultural etc. - se constituam como uma ordem coletiva baseada em padrões mínimos de respeito e confiança, e não nos primados da competitividade e da produtividade levadas ao extremo, do individualismo sem freios e da disseminação dos valores de mercado em todas as esferas da vida, como hoje ocorre com o fenômeno da globalização.

A possibilidade de efetuar interpretações alternativas da realidade existente é, nessa linha de raciocínio, uma das características do princípio da reciprocidade. No caso específico dos direitos humanos, tal possibilidade permite alargar e ultrapassar os limites das concepções de caráter juridicista que continuam animando muitos grupos e movimentos dispostos a resistir quer à violação e ao desmonte de garantias básicas dos cidadãos, quer ao impacto desmobilizador da racionalidade técnico-instrumental inerente à transnacionalização dos mercados. Valorizando novas pautas hermenêuticas para a interpretação da realidade sócio-econômica, as concepções de direitos humanos de caráter não-juridicista vão muito além da simples denúncia das ilusões homogeneizadoras que permitem à sociedade se representar sob a imagem de uma ordem funcionalmente integrada, unívoca, sob a égide de um texto constitucional. Tais concepções, por exemplo, recolocam a idéia de justiça no centro das discussões - não mais justiça abstrata, fundada em critérios metafísicos ou transcendentes, mas justiça in fieri, pensada com base em situações concretas e com perspectivas históricas específicas. E enfatizam a importância da reciprocidade como um processo que permite combinar formas indivi- 
duais com formas coletivas de cidadania, transformando e ampliando o conceito ao criar condições para a formação de poderes sociais capazes de se contrapor ao poder privado e particularista do capital, compensando assim a erosão da soberania dos Estados-nação na nova ordem econômica internacional.

No momento em que os imperativos categóricos da transnacionalização dos mercados e da plenitude democrática se chocam e se excluem, os direitos humanos, por isso mesmo, estão vivendo uma situação de curiosa ambigüidade. Se no plano estritamente jurídico-positivo o panorama parece sombrio e cinzento, uma vez que estão sendo vitimados pelos já mencionados processos de desregulamentação, deslegalização e desconstitucionalização atualmente promovidos pelos Estados-nação para melhor se adaptar às exigências da globalização econômica, o mesmo já não ocorre no plano político. Aqui os direitos humanos seguramente continuarão constituindo importante critério para animar e orientar as lutas em prol da revitalização da liberdade e da dignidade humana.

Referências bibliográficas

ADORNO, Sérgio. A gestão urbana do medo e da insegurança: violência, crime e Justiça Penal na sociedade brasileira contemporânea. São Paulo, 1996. Tese (livre-docência), Faculdade de Filosofia, Letras e Ciências Humanas da USP.

BENDIX, Reinhard. Nation-building and citizenship: studies of our changing social order. Berkeley, University of California Press, 1977.

CAPELLA, Juan Ramón. Los ciudadanos siervos. Madrid, Editorial Trotta, 1993.

FERRY, Luc \& RENAULT, Alain. Des droits de l'homme à l'idée républicaine. Paris, Press Universitaires de France, 1985.

GALGANO, Francesco; TREMONTI, Giulio; CASSESSE, Sabino \& TREO, Tiziano. Nazioni senza ricchezza, ricchezze senza nazioni. Bologna, Il Mulino, 1993.

GESSNER, Volkmar. Legal certainty in cross-border interactions. ISA-RCSL 95 ANNUAL MEETING, Proceedings of 1995. Tokio, International Sociological Association, Research Committe on Sociology of Law, 1995.

LATOUCHE, Serge. A ocidentalização do mundo: ensaio sobre a significação, o alcance e os limites da uniformização planetária. Petrópolis, Vozes, 1996.

LECHNER, Norbert. Los nuevos perfiles de la politica: un bosquejo. Santiago, Flacso, Documento de Trabajo, n. 31, 1993.

OLGIATI, Vittorio. Towards a new universitas mercatorum: the political economy of the Chamber of Commerce of Milan. Milano, I Quaderni di Impresa e Stato, 1997.

PETRELLA, Ricardo. Globalization and internationalization: the dynamics of the emerging world order. In: BOYER, Robert \& DRACHE, Daniel (orgs.), States against markets. London, Routledge, 1996.

SANTOS, Boaventura. Toward a new common sense: law, science and politics in the paradigmatic transition. London, Routledge, 1995. 
TEUBNER, Gunther. Juridification of social spheres: a comparative analysis in the areas of labour, corporate, antitrust and social welfare law. Berlim, Waleter de Gruyter, 1987.

TEUBNER, Gunther. Droit et réflexivité: l'auto-réference en droit et dans l'organisation. Paris, Librairie Génerale du Droit et Jurisprudence, 1996.

WILLKE, Helmut. The tragedy of the State: prolegomena to a theory of State in polycentric society. In: ARSP-Archiv für Rechts und Sozialphilosophie. Stutgart, v. LXXXII, 1986.

RESUMO - O objetivo deste artigo é avaliar o impacto da globalização sobre os direitos humanos. Historicamente, como é sabido, eles foram criados contra o Estado, ou seja, como forma de coibir a interferência arbitrária do poder público na esfera individual. Mas como a globalização relativizou a soberania do Estado e reduziu drasticamente sua força coercitiva, qual é o futuro dos direitos humanos nesse contexto sócio-económico?

ABSTRACT - This article attempts to draw attention to what has been globalization and avaluate the impact of this phenomenon on Human Rights. Historically, this kind of fundamental legal garantees, known as Human Rights, were created against the NationState, that is to say, they were conceived to protect citizens against the arbitrariness of public power. However, in so far globalization has undermined the sovereignity of the Nation-State and has decreased the coercitive force of the public power, what is the future of Human Rights in this new social and economic context?

José Eduardo Faria é professor associado do Departamento de Filosofia e Teoria Geral do Direito da USP, pesquisador do Centro de Estudos Direito e Sociedade (Cediso) e autor de Direito e economia na democratização brasileira, A crise do direito numa sociedade em mudança e Globalização econômica e direito. 